\title{
DANÇA E EDUCAÇÃO: DIMENSÕES ÉTICO-ESTÉTICAS DO CORPO
}

\author{
Vitor Hugo Marani \\ Universidade Federal de Mato Grosso, Pontal do Araguaia, Mato Grosso, Brasil \\ Antonio Carlos Monteiro de Miranda \\ Universidade Estadual de Maringá,. Maringá, Paraná, Brasil
}

\begin{abstract}
Resumo
O texto foi orientado pelas interfaces entre dança e educação, a fim de problematizar as dimensões ético-estéticas do corpo no contexto do ensino da dança na escola. Especificamente, atentou-se à reflexão sobre o ensino da dança na escola e à discussão referente à dimensão ético-estética do corpo que se instaura como elemento educacional para se pensar a dança como meio para unir sensibilidade à racionalidade. Para tanto, a pesquisa, de caráter bibliográfico, foi guiada por leituras de obras relacionadas à dança, à educação e ao sentido éticoestético do corpo. Concluiu-se que a educação ético-estética por meio da dança pode contribuir para a valorização do sensível e da criação na cultura do corpo como formas de mudança no paradigma da dança no tempo-espaço escolar.
\end{abstract}

Palavras-chave: Dança. Dimensão Ético-estética. Educação.

\section{DANCE AND EDUCATION: ETHICAL-AESTHETIC DIMENSIONS OF THE BODY}

\begin{abstract}
The text was oriented by the interfaces between dance and education, in order to problematize the ethical and aesthetic dimensions of the body in the context of the teaching of dance in the school. Specifically, it focused on the reflection on the teaching of dance in the school and the discussion regarding the ethical-aesthetic dimension of the body is established as an educational element to think of dance as a means to unite sensitivity to rationality. To do so, the research, of bibliographic character, was guided by readings of works related to dance, to education to the ethical-aesthetic sense of the body. It was concluded that ethical-aesthetic education through dance can contribute to the appreciation of the sensitive and the creation in the culture of the body as forms of change in the paradigm of dance in school time-space.
\end{abstract}

Keywords: Dance. Ethical-aesthetic dimensions. Education.

\section{DANZA Y EDUCACIÓN: DIMENSIONES ÉTICO-ESTÉTICAS DEL CUERPO}

\section{Resumen}

El texto fue orientado por las interfaces entre danza y educación, a fin de problematizar las dimensiones ético-estéticas del cuerpo en el contexto de la enseñanza de la danza en la escuela. Específicamente, se atentó a la reflexión sobre la enseñanza de la danza en la escuela ya la discusión referente a la dimensión ético-estética del cuerpo se instaura como elemento educativo para pensar la danza como medio para unir sensibilidad a la racionalidad. Para ello, la investigación, de carácter bibliográfico, fue guiada por lecturas de obras relacionadas a la danza, a la educación al sentido ético-estético del cuerpo. Se concluyó que la educación ético- 
estética por medio de la danza puede contribuir a la valorización de lo sensible y de la creación en la cultura del cuerpo como formas de cambio en el paradigma de la danza en el tiempo-espacio escolar.

Palabras clave: Danza. Dimensiones ético-estéticas. Educación.

\section{Introdução}

A colonização da ética e da estética pela ciência moderna demarca novas formas de materialização das ações do humano na sociedade contemporânea. Trata-se, como observa Goergen (2010), de uma crise da razão, assimilada em sua dimensão cada vez mais instrumental, delineando um novo paradigma para pensar a concretização das práticas sociais na modernidade. ${ }^{1}$ Inauguram-se, a partir desse momento, novas problemáticas que tocam à tematização do corpo e das manifestações corporais, configuradas em meio a processos normativos que explicitam modos próprios de existência e que representam formas culturais inscritas em novas expressões da educação, do trabalho, do lazer ou outros.

Decorrente dessas mudanças, em que novos contornos da realidade são estruturados, como observa Goergen (2010), Lara (2010) instaura a ideia de uma educação em que, a partir do diálogo na cultura do corpo, ${ }^{2}$ seja possível alcançar a valoração das dimensões ética e estética do humano, de modo a transcender o pensamento baseado na razão ocidental que visualiza a sensibilidade como necessidade inferior. Dessa educação do corpo na modernidade, extrai-se a possibilidade de pensar as diferentes manifestações corporais consolidadas no tempoespaço escolar que, embora possam contribuir, como elucidado por Lara (2010), para uma educação voltada às interfaces entre sensível e inteligível, transgressivo e normativo, acabam, de acordo com o formato assumido, contribuindo para a instrumentalização do humano. ${ }^{3}$

Dentre as diversas expressões da cultura do corpo presentes na escola, o texto atentase à tematização da dança, visualizando nela a possibilidade de discussão ético-estética das práticas corporais. ${ }^{4}$ Conforme explicita Guzzo et al. (2015), a dança pode ser compreendida como ação política para a cultura corporal a partir do movimento crítico que faz em relação à realidade, questionando ou propondo possibilidades de ação e transformação da existência humana, o que evidencia o potencial ético no campo escolar. Pelo olhar estético, a dança se materializa, segundo Rocha e Rezer (2015), pela possibilidade de qualificar um olhar sensível para a educação, por meio de uma reeducação dos sentidos permeada pela reflexão filosófica.

Sob tal possibilidade discursiva, a interação entre ética e estética ${ }^{5}$ contribui para pensar o processo de ensino da dança na escola, inserido num contexto amplo de educação do corpo, que transcenda a mera reprodução de movimentos, muitas vezes, alheios ao conhecimento dos educandos que fazem parte do processo pedagógico. Por isso, a necessidade de

\footnotetext{
${ }^{1}$ A partir das contribuições de Leandro Chevitarese, compreende-se a modernidade como conjunto de ideais, pós-Iluminismo, que reflete a racionalidade científica posta às relações e às diversas esferas sociais e que acabam por impactar diretamente o campo da cultura.

${ }_{2}^{2}$ A proposta de educação pelo diálogo, tratada tanto no texto de Goergen (2010) quanto no texto de Lara (2010), está apoiada nas contribuições teóricas de Jürgen Habermas e sua teoria da ação comunicativa, que pressupõe a linguagem como mediadora da verdade a partir de processos discursivos e intersubjetivos.

${ }^{3} \mathrm{Na}$ educação física, o furto de tais dimensões decorre da mecanização da gestualidade pela técnica, da erotização do corpo, da falta de reflexão sobre as manifestações corporais, da supremacia de algumas práticas em detrimento de outras e da redenção a modelos que valorizem apenas o hegemônico.

${ }^{4}$ Embora o texto eleja a dança como eixo, entende-se que é apenas uma das vias, uma vez que a ginástica, o jogo, o esporte, a luta, o lazer, a saúde, entre outros, podem ser reconhecidos como meio para a discussão éticoestética.

${ }^{5}$ Entende-se, a partir das contribuições de Lara (2007, p. 115), "a ética como filosofia moral que lida com investigações acerca de regras e valores mais gerais [...] a estética foi visualizada como teoria filosófica das formas de manifestação do sensível [...] por meio de leis, padrões e regras que regem suas relações com o humano".
} 
apontar o fazer pedagógico em dança como uma possibilidade do (re)conhecimento do corpo na escola, emergindo, como sugere Strazzacappa (2003), como conteúdo que não se finda nas apresentações escolares em datas comemorativas, mas que seja refletida como parte do desenvolvimento da criatividade, da improvisação e da experiência estética, o que supera o analfabetismo teórico-reflexivo encontrado na área da dança.

Ainda, nos dizeres de Brasileiro (2003), por meio da dança, as ações corporais cotidianas acabam por serem (re)significadas, o que transcende a ótica da dança como mera reprodução de sequência de movimentos corporais, executados de maneiras ritmadas, o que conduz a uma dimensão poética do corpo - dimensão do sagrado, que foge à lógica profana, da instrumentalização de si, do outro, do tempo e do espaço. Da análise sociocultural, evidencia-se a proposta em observar o campo de tensões que deve ser analisado criticamente, com o intuito de desvendar os códigos simbólicos pelos quais a dança se estrutura, o que atribui novos sentidos e significados para que seja uma experiência significativa, conforme explica Sborquia e Gallardo (2006), quando discute a perspectiva da dança como parte da educação e da educação física na escola.

Desse pensamento, deflagra-se a ideia do ensino da dança que se instaura a partir do olhar sobre a educação e o diálogo na cultura do corpo, entendendo que tais dimensões, durante séculos, foram obscurecidas pelo pensamento religioso e pela ciência, o que camuflou sua racionalidade estético-expressiva e propagou a sensibilidade como necessidade inferior à condição humana. Por isso, a necessidade de uma educação voltada à dança como manifestação resistente à homogeneização das experiências educativas, configurando-se como meio de valorização da pluralidade (LARA, 2010).

Partindo desse pressuposto, o texto tem como objetivo investigar interfaces entre dança e educação, a fim de problematizar as dimensões ético-estéticas do corpo no contexto do ensino da dança na escola. Para tanto, a pesquisa, de caráter bibliográfico, foi orientada por leituras de obras relacionadas à dança, à educação, à cultura e ao sentido ético-estético do corpo. Do delineamento da pesquisa, o artigo estrutura-se a partir de três seções. A primeira almeja refletir sobre o ensino da dança em suas interfaces com a escola. A segunda atenta-se à construção cultural do corpo e como tal entendimento pode contribuir para a tematização da dança como elemento da cultura corporal. E, por fim, a discussão referente à dimensão éticoestética do corpo se instaura como elemento educacional para pensar a dança como meio para unir sensibilidade à racionalidade.

\section{Reflexões sobre o ensino da dança na escola}

As relações entre dança, escola e educação física, embora emerjam com intensidade na produção científica e na intervenção profissional na década de 1990, fazem-se presentes desde o final do século XIX e início do século XX, período em que as práticas corporais integravam um modelo de educação do corpo (STRAZZACAPPA, 2003). Voltada à preparação para trabalho e para a formação da identidade nacional, essa educação corporal, conforme explica Soares (1994), pressupunha a eugenia da raça no país e a higiene da população por meio do uso da ginástica e do exercício físico em diferentes tempos e espaços - primeiramente no tempo de não trabalho e, posteriormente, na escola.

Sob tal paradigma, a dança, comumente apreendida na forma de atividades rítmicas e ligada ao exercício físico, contribuía para a educação corporal atrelada aos métodos ginásticos europeus, notoriamente, ao método francês, quando se utilizava das danças para o cuidado, principalmente, do corpo feminino, como alerta Soares (1994). Na mesma direção, Morandi (2006) evidencia o papel exercido pela dança durante a adoção dos métodos ginásticos na escola, cujo enfoque estava na acentuação da graciosidade do movimento e no trato de dimensões biológicas do corpo para futura maternidade. 
Essa perspectiva fez-se presente até o momento da Segunda Guerra Mundial, uma vez que, após seu findar, o modelo esportivo, pautado na seleção de atletas e no rendimento, passou a integrar o projeto de educação física escolar brasileira, ressaltando, como afirma Daolio (2003), os aspectos biológicos do corpo, em detrimento dos aspectos socioculturais nele presentes. A construção de uma educação física voltada ao rendimento esportivo fez com que as outras manifestações corporais estivessem ausentes no ambiente escolar ou, no mínimo, marginalizadas, como descreve Sborquia e Gallardo (2006). Decorre dessa ideia que a dança, assim como a ginástica, ganhava destaque na dinâmica educacional apenas quando adotava os mesmos princípios do esporte, a exemplo da competição, da técnica exacerbada e da repetição de movimentos. Tal perspectiva pode ser evidenciada, como sugerem Sborquia e Gallardo (2006), pela pedagogia tecnicista adotada pelas escolas brasileiras da década de 1970.

É no início da década de 1980, fruto do momento de redemocratização do país e de liberdade de pensamento, que mudanças sociais tomam corpo e passam a introduzir na educação modelos críticos que visassem ao rompimento com as pedagogias adotadas na escola até então (LARA; VIEIRA, 2010). Desse período, como descreve Daolio (2003), decorrem inquietações que passam a problematizar o ensino da educação física na escola, bem como os pressupostos que norteavam as ações pedagógicas dos professores. Assim, contribuições teóricas demarcam o início de uma nova fase epistemológica da educação física, a exemplo de Medina (1983) e Oliveira (1983). No que diz respeito às novas formulações relacionadas à dança, Lara e Vieira (2010) lembram da obra de Claro (1988), quando estrutura o método dança-educação física e aborda questões relacionadas à formação profissional e à experimentação de novas formas educacionais.

A partir dessa década, novas formulações teóricas passaram a compor o cenário da educação física e, junto desse movimento, o trato com a dança também acaba por ocupar seu espaço. ${ }^{6}$ Fruto desse momento, é mister lembrar das contribuições realizadas pelo grupo de intelectuais da educação física que propuseram a sistematização dos conteúdos da educação física escolar brasileira, conhecidos como Coletivo de Autores. Em 1992, a partir da publicação da obra Metodologia do ensino da educação física, como discutem Lara e Vieira (2010), a dança é visualizada como o mesmo grau de importância que as outras manifestações da cultura corporal. Posteriormente, outras propostas acenam para pensar a dança junto à educação física, dentre elas as de Betti (1991), Kunz (1994) e Daolio (2003), que apresentam avanços em relação ao trato com esse conhecimento.

Em 1997, com a publicação dos Parâmetros Curriculares Nacionais (PCNs), a dança é apresentada tanto como conteúdo pertencente à educação física quanto à arte e, embora apareça de maneira distinta nos documentos, existem pontos convergentes, principalmente no que toca à dança como produção artístico-cultural, como trata Strazzacappa (2003). No documento que trata dos conteúdos relacionados à educação física, a dança está presente no bloco intitulado "atividades rítmicas e expressivas". As atividades rítmicas e expressivas incluem as manifestações da cultura corporal que têm como características comuns a intenção de expressão e comunicação mediante gestos e a presença de estímulos sonoros como referência para o movimento corporal, como trata o documento.

A partir do documento elaborado em esfera nacional, documentos estaduais e regionais começaram a ser confeccionados, como explica Strazzacappa (2003), e, com isso, a dança passou a fazer parte das normativas e resoluções em diferentes estados e cidades do país. Como é evidenciado em pesquisa realizada por Diniz e Darido (2015), ao analisarem Propostas Curriculares Estaduais (PCEs) de 17 estados brasileiros, permitindo compreender como a dança é abordada em todo o país por meio dos elementos apontados nos documentos oficiais

\footnotetext{
${ }^{6}$ Mesmo que a dança não estivesse consolidada na escola, é importante acenar sua posição na formação inicial em educação física, desde os anos de 1940, junto à Escola Nacional de Educação Física da Universidade do Brasil, por meio da figura da professora Maria Helena Pabst de Sá Earp (LARA; VIEIRA, 2010).
} 
que regulamentam os currículos das escolas estaduais brasileiras. Embora os resultados apontem que a dança é um conteúdo relevante para as PCEs, já que todas propuseram esse tema em suas diretrizes, Diniz e Darido (2015) apontaram que os objetivos, o referencial teórico e as dimensões dos conteúdos apresentaram divergências entre si.

Para além dos documentos, houve, no referido período, o aumento da produção de conhecimento relacionada à dança, principalmente no que diz respeito a formulações teóricopráticas relacionadas ao tratamento desse conteúdo no ambiente escolar. Dentre as principais produções, destacam-se as contribuições de Marques (1999; 2003), Barreto (2004), Sborquia e Gallardo (2006), Strazzacappa (2002-2003) e Nanni (2003), que, de uma maneira ou outra, apropriam-se da dança para pensá-la no contexto da formação inicial e da educação básica, possibilitando ferramentas para professores que atentam-se aos processos pedagógicos relacionados à manifestação da dança.

São notórios os avanços identificados no campo normativo da dança em interface com o campo escolar por meio da visualização de documentos e obras que orientem não apenas sua presença na escola, mas indiquem possibilidades didático-pedagógicas e técnicoinstrumentais do referido conteúdo. Todavia, a marginalização da dança no modus operandi da escola e, principalmente, na educação física ainda precisa ser debatida. É comum esbarrarse com apropriações do conteúdo da dança como mera atividade de reprodução de movimentos, ou atividade demasiadamente livre, ou performance ligada a apresentações que visem demarcar dado evento comemorativo, como lembram Souza (2011) e Strazzacappa (2003). Tal denúncia também foi realizada por Marques (1999), quando discute a dança ora com caráter de cópia alienada com valorização excessiva do fazer artístico mecânico e predeterminado, ora creditada às práticas "espontâneas", sem fundamentação teórica e/ou técnica.

Apesar de legalizada por meio de leis e normativas que orientam a sistematização desse saber na escola, a dança emerge, nesse contexto, com características que remetem à sua manifestação como produto e não como processo de ensino e aprendizagem. Embora tais constatações sejam evidenciadas, é preciso que novas proposições sejam estabelecidas, construídas com base na materialização da dança na escola - dilemas, desafios e perspectivas rumo a formas que se deflagram na perspectiva de um ensino de qualidade, cujo foco esteja na sensibilização, na experimentação e na criação dos indivíduos envolvidos no processo de ensino-aprendizagem da dança na escola (ZOTOVICI, 1999).

A partir das proposições, aponta-se a consolidação de experiências necessárias para a formação do indivíduo para além do caráter instrumental das práticas corporais, comumente observado na escola. Assim, reside a importância da dança no contexto educacional sem perder com isso seu sentido artístico, estabelecendo, conforme explica Souza (2011), relações com a arte que extrapolam o espaço da sala de aula, assumindo o papel de ser um canal de ampliação da sensibilidade e da percepção do mundo, integrada ao desenvolvimento das habilidades corporais. Tais habilidades, no processo educacional, não estão destituídas do reconhecimento das regras e valores estabelecidos socialmente e que acabam levando à criação de estéticas corporais, assumindo formas de agir, pensar e se expressar em diferentes contextos sociais, dentre eles, na escola.

\section{Dimensões ético-estéticas no ensino da dança na escola ${ }^{7}$}

A construção do retrato da dança junto ao ensino e sua apropriação a partir de uma proposta educacional embasada na cultura emergem como pilar para pensar sobre as dimensões ético-estéticas de uma educação corporal projetada no ensino da dança. O pensamento

\footnotetext{
${ }^{7}$ Neste tópico, serão apresentadas ideias reflexas das contribuições de Lara $(2010 ; 2011)$ para pensar sobre o corpo e seu sentido ético-estético - categorias centrais para refletir acerca do processo de ensino da dança eleito na pesquisa. Por isso, o diálogo com a autora aparece com densidade no texto.
} 
que vê a educação ético-estética como categoria importante no cenário escolar intensifica-se a partir da visualização de um corpo que, na sociedade contemporânea, encontra-se demasiadamente pautado por sua instrumentalização, pelo não reconhecimento do outro e pela ausência do elemento lúdico na vida cotidiana e que, por isso, necessita ser problematizado.

Pensar a dimensão ética e estética da dança, nesse sentido, dá-se por um processo educativo que rompa com práticas pedagógicas focalizadas na dimensão técnico-instrumental da referida manifestação corporal. Tem-se, rumo a outra racionalidade, o entendimento do corpo em seu sentido ético-estético - termo cunhado por Lara (2011) -, que assinala o campo gestual como fruto das normativas sociais, não destituído das sensações, percepções e criações dos indivíduos, o que ressalta as interlocuções entre ética e estética e não submissão de uma a outra, como normalmente observado na sociedade ocidental.

Tais dicotomias, embora oriundas do pensamento filosófico grego, foram acentuadas em diferentes períodos históricos, ${ }^{8}$ o que culminou na presença da ideia de um humano demasiadamente preso às regras e imposições sociais que, por vezes, visualiza a dimensão corpórea como inferior. Por isso, a ideia de estabelecer as relações entre ética e estética na educação do corpo como recurso para unir razão e sensibilidade, o que pode contribuir para a formação do corpo, não no sentido que se restringe ao físico, mas em sua totalidade (LARA, 2011). Daí a necessidade de materialização da dança no tempo-espaço escolar, contribuindo para a percepção ético-estética dos educandos e favorecendo uma educação que não se esgote numa pedagogia meramente instrumental, que "naturaliza" a marginalização das práticas corporais.

A construção do ensino da dança na escola orienta-se pela construção de um corpo ético-moral e estético-expressivo, tomando por base as ideias de Lara $(2007 ; 2010 ; 2011)$ e Roble (2009), ambas desenvolvidas a partir da obra Assim falou Zaratustra, de 1883, do filósofo alemão Friedrich Nietzsche (1844-1900). Em Nietzsche (2005), tem-se a narrativa do profeta Zaratustra que, após dez anos de isolamento, vê-se cheio de conhecimento e desce da montanha para proclamar "a morte de Deus", a criação do super-homem e o desejo de potência. ${ }^{9}$ Percebe-se, em decorrência dessa busca, o surgimento de um ser humano que não é escravizado, nem à ciência e nem à religião, valorizado em sua sensibilidade, expressa em sua dimensão ética e estética, como explica Lara (2011).

Dessa perspectiva, decorre a ideia do corpo - e, logo, da dança - em sua interface criadora, atestada das dimensões ético-estéticas, capazes de alcançar o entrelace entre as figuras dos deuses mitológicos da cultura grega Dionísio e Apolo. Tais figuras são trazidas nas obras de Friedrich Nietzsche e representam, respectivamente, a desordem e a contestação e a harmonia do agir dentro das normas. As representações dos deuses gregos para o filósofo atende à necessidade de complementação dessas figuras, embora a sociedade ocidental tenha valorizado uma figura em detrimento da outra.

O potencial dionisíaco é representado, em Nietzsche (2005), pela metáfora da dança, que ocupa papel de destaque na estória de Zaratustra. Pela análise de Roble (2009), a dança aparece como categoria que transcende o recurso de linguagem, pois é vislumbrada como fenômeno educativo e transformador. É eleita por Nietzsche (2005), nos dizeres de Roble (2009), como uma das possibilidades para que o humano supere sua condição de fraco, para ir além da moral de rebanho, para atingir a metáfora do "super-homem", ocupando papel de protagonistas em suas próprias vidas.

Pelas teias construídas via leitura de Nietzsche (2005), Roble (2009) constata que Zaratustra, em meio às suas andanças, buscava ensinar ao humano que é necessário dançar para

\footnotetext{
${ }^{8}$ Cf. Lara (2011), capítulo 1, ao discutir as relações histórico-filosóficas entre ética e estética.

${ }^{9}$ A morte de Deus incide na negação dos princípios e imposições proclamados durante séculos pelo cristianismo. Por isso, a necessidade de criação do super-homem, sua segunda metáfora, que pressupõe a vida de um ser conciliado com seu corpo e possuidor integral de suas forças, desejoso de potência criadora (LARA, 2011).
} 
que seja permitido elevar-se ao divino e transcender-se da esfera mundana. ${ }^{10}$ A crítica do filósofo, segundo Roble (2009), reside no fato de que, na cultura judaico-cristã, toda forma de aproximação do elemento divino por meio de práticas corporais foi conduzida à categoria do profano, contribuindo para a formação de uma racionalidade ocidental cujo foco estava exclusivamente na razão.

A crítica elucidada nas obras de Friedrich Nietzsche, embora pertença ao final do século XIX, ainda pode ser trazida à tona no século XXI. A valorização de uma educação cujo foco esteja na razão emerge na sociedade contemporânea e é responsável por processos educacionais que aprisionam o corpo e suas práticas, tomando-as como conhecimentos marginalizados. É demarcado, como Lara (2010), o pensamento que impõe o pensar em detrimento do fazer, da seriedade em detrimento da brincadeira e do criar - fruto das condições da valorização da racionalidade apolínea diante da racionalidade dionisíaca. A efetivação do ato criativo, visualizado pela condição da desordem, aniquila a produção de uma educação vista como séria e, por isso, não encontra espaço na educação da razão, como reflete a autora.

É necessário romper com estratégias pedagógicas que utilizam a dança apenas em sua expressão racional, por isso, as contribuições de Zaratustra podem ser trazidas a esse contexto, uma vez que dizem respeito às relações entre campo sensível e racional que conduzem à nova concepção de ser humano, diferente daquele que se encontra em posição de inferioridade ou menoridade perante o outro ou a algo. A reflexão sobre a cultura do corpo como campo educacional e intercomunicativo que se configura como "outra racionalidade", apresentado nos escritos de Lara (2010), atenta para formas diferenciadas de conhecimento que acabam sendo subjugadas numa sociedade em que tudo foge à ótica racional, de explicação lógica, tende a ser banalizado e julgado como fonte inferior de saber.

Dentre as possibilidades do processo educacional da dança, em que as dimensões ético-estéticas do corpo estejam presentes, destacam-se os processos criativos que podem ser evidenciados nas contribuições de Zotovici (1999), Strazzacappa (2003), Marques (1999, 2003), Morandi (2006), entre outros. Como fato consensual, as autoras entendem que tais processos não devem ser entendidos como produtos do trato pedagógico, mas como estratégias em que os educandos sejam vistos como indivíduos responsáveis por suas ações em cena, livres para realizar escolhas e protagonistas, assim como propõe Zaratustra na obra de Nietzsche (2005).

A criação de condições favoráveis para que a dança seja vivenciada de forma criativa não exclui, como explica Marques et al. (2014), as formas de aprendizagem que trazem consigo elementos das técnicas específicas da dança, mas, ao contrário, revela alternativas para a construção de estratégias pedagógicas que permitam seu desenvolvimento, numa aprendizagem dialógica, que respeite as individualidades. Há, com base nos autores, a ênfase da exploração dos movimentos criados pelos próprios sujeitos, essencialmente, voltados ao "fazer", ao pesquisar, ao experimentar, ao improvisar, o que estimula a sensibilidade e o desejo de novas sensações corporais, as quais, conforme explicitado na dimensão ético-estética do corpo, não estão alheias às regras e às normas da sociedade.

Essa educação do sentido ético-estético do corpo alia-se ao compromisso de não aceitar que apenas as reproduções de modelos de danças expostas pela mídia, ou padrões de movimentos específicos, se façam presentes no contexto escolar, como relata Marques et al. (2014). Nessa perspectiva tecnicista, de mera reprodução sem fins criativos, Johann (2015) alerta para o empobrecimento das dimensões ético-estéticas da educação, uma vez que essa

\footnotetext{
${ }^{10}$ No caso da interpretação nietzschiana, Roble (2009) explica que essa transcendência não é a do espírito que abandona o corpo tal qual na tradição cristã. O corpo é objeto central na relação com o transcendente nas festas sagradas entre os gregos, e a dança é uma das formas de elevar as potências corporais até o nível da harmonia divina.
} 
forma de ensino não favorece o contato primário com as formas artísticas - ato criado pelo aluno - mas apenas com a cópia, como fenômeno pronto e acabado. Por isso, a contribuição do ato criador na escola é relevante, pois, conforme sugere Johann (2015), atribui ao educando a força para interrogar padrões, valores, concepções e gostos, exigindo reflexão éticoestética e fazendo com que a abordagem instrumental assuma uma dimensão secundária do processo educativo.

A partir das condições apresentadas, pode-se contribuir para uma educação consciente, voltada para a valorização do sensível e da criação na cultura do corpo, possibilitando a tessitura de novos sentidos e significados ao gesto, compreendido em sua dimensão históricosocial. A dança, quando guiada pelo sentido ético-estético do corpo, poderá conduzir, junto a outras manifestações corporais, à percepção ampliada do humano, da criação, do reconhecimento de si a partir da coletividade. Rompe-se, como sugere Lara (2010), com o individualismo, com a homogeneidade de pensamentos e com uma educação em seu sentido apolíneo da racionalidade técnica - que furta o lúdico e nega as manifestações do corpo.

Por fim, o entendimento ético-estético do corpo faz com que as práticas corporais, apreendidas em diferentes contextos, sejam captadas pela compreensão de humano que somente é completo em meio às suas contradições dionisíacas e apolíneas, como sugere a figura de Zaratustra (NIETZSCHE, 2005). Deflagra-se, por esse pensamento, a necessidade de compreender a dança na escola por meio das tensões entre razão e sensibilidade, cujo embasamento pedagógico consiga exaltar ética e estética como formas de mudança no paradigma da educação corporal, contribuindo para a experiência criativa e a vivência lúdica e entendendo tais categorias como dimensões necessárias para a formação humana.

\section{Considerações finais}

O interesse central da pesquisa esteve voltado às dimensões ético-estéticas do corpo no contexto da dança na escola no sentido de direcionar olhares para o modo como essas dimensões emergem na educação e na educação física com base nos conhecimentos advindos da literatura que versa sobre o tema. Tal anseio investigativo possibilitou a apreensão da dança e do campo gestual em sua dimensão poética a partir da união entre razão e sensibilidade, condições necessárias para romper com a educação instrumentalizada, cada vez mais presente na educação contemporânea.

Do delineamento da pesquisa, o artigo estruturou-se a partir de três seções. A primeira refletiu sobre o ensino da dança e suas interfaces com a escola, entendendo que tais relações não são recentes, mas fruto de um processo de sistematização da educação do corpo com fins instrumentais para o instaurar da ordem no país. Ganhou notoriedade a partir de publicações de autores da área - Castellani Filho et al. (1992) - e de documentos norteadores (BRASIL, 2000), que revelaram seu potencial junto a outras manifestações corporais que poderiam ser eleitas como conteúdos da cultura corporal, o que favoreceu, de um modo ou outro, o ingresso da dança no contexto escolar.

A discussão referente à dimensão ético-estética do corpo instaurou-se como elemento educacional para pensar a dança como meio para unir sensibilidade à racionalidade, numa perspectiva de valorizar a dimensão dionisíaca da educação, cuja ênfase pode ser dada a partir da dança, não em sua potencialidade ordeira e meramente reprodutora de gestos, mas em sua expressão criadora e transgressiva, assinalada pela razão que se atente à razão dionisíaca. $\mathrm{Pe}$ las contribuições de Lara $(2010$; 2011) e Roble (2009), via Nietzsche (2005), foi possível abrir possibilidades para pensar os sentidos do corpo para além de sua conotação marginalizada na sociedade, vislumbrando uma educação ético-estética que favoreça a ludicidade, o espontâneo e o criar, categorias basilares para refletir sobre o ensino da dança na escola. 
Entende-se que as ideias apresentadas no texto, embora não sejam utilitárias e pragmáticas, fomentam novas formas de pensar e agir sobre o corpo que se expressa na escola, bem como atentam-se a problematizações que podem servir de orientação para o trato pedagógico da dança nesse tempo-espaço. Nessa perspectiva, o aflorar da criatividade na escola pode nortear ações pedagógicas em dança, como maneira de permitir a vivência lúdica e artística como transgressão de ações repetitivas do cotidiano, compreendendo que tais experiências não ocorrem desprovidas das tensões constitutivas entre sensível e racional, o que inaugura espaços baseados em "outras" experiências corporais.

\section{Referências}

BARRETO, D. Dança: ensino, sentidos e possibilidades na escola. Campinas: Autores Associados, 2004.

BETTI, M. Educação física e sociedade: a educação física na escola brasileira de $1^{\circ}$ e $2^{\circ}$ graus. São Paulo: Movimento, 1991.

BRASIL. Ministério da Educação. Parâmetros Curriculares Nacionais para o Ensino Fundamental. Brasília: MEC/SEF, 2000.

BRASILEIRO, L. T. O conteúdo dança em aulas de educação física: temos o que ensinar? Pensar a Prática, Porto Alegre, v. 6, n.1, p. 45-58, jul./jun. 2002; 2003.

CASTELlani FILHO, L. et. al. Metodologia do ensino de educação física. São Paulo: Cortez, 1992.

CLARO, E. Método dança-educação física: uma reflexão sobre consciência corporal e profissional. São Paulo: Robe Editorial, 1988.

DAOLIO, J. Da cultura do corpo. Campinas: Papirus, 2003.

DINIZ, I. K. S.; DARIDO, S. C. Análise do conteúdo dança nas propostas curriculares estaduais de educação física do Brasil. Revista da Educação Física, UEM, v. 26, p. 353-365, 2015. Disponível em: < http://www.periodicos.uem.br/ojs/index.php/RevEducFis/article/view/25385>. Acesso em: fev. 2017.

GOERGEN, P. Educação e diálogo. In: GOERGEN, P. Educação e diálogo. Maringá: Eduem, 2010.

GUZZO, M. S. L.; FEDERICI, C. A. G.; ROBLE, O. J.; TERRA, V. D. S. Dança é política para a cultura corporal. Pensar a Prática, Goiânia, v. 18, n. 1, jan./mar. 2015.

KUNZ, E. Transformação didático-pedagógica do esporte. Ijuí: Unijuí, 1994.

JOHANN, M. R. Arte e Educação: perspectivas ético-estéticas. In: Associação Nacional de Pós-Graduação e Pesquisa em Educação - ANPED, 2015, Florianópolis - SC. Plano Nacional de Educação: tensões e perspectivas para a educação pública brasileira, 2015. 
LARA, L. M. O sentido ético-estético do corpo na cultura popular e a estruturação do campo gestual. Movimento, Porto Alegre, v. 13, p. 111-129, 2007. Disponível em: < http://www.seer.ufrgs.br/index.php/Movimento/article/view/3570>. Acesso em: jan. 2017.

Educação e diálogo na cultura do corpo. In: GOERGEN, P. (Org.) Educação e diálogo. Maringá: Eduem, 2010.

Corpo, sentido ético-estético e cultura popular. Maringá: Eduem, 2011.

; VIEIRA, A. P. Em foco... o corpo que dança: experiências docentes e intersubjetividades desafiadas. In: LARA, L. M. (Org.). Abordagens socioculturais em educação física. Maringá: Eduem, 2010.

MARQUES, I. Ensino de dança hoje: textos e contextos. São Paulo: Cortez, 1999.

Dançando na escola. São Paulo: Cortez, 2003.

MARQUES, D. A. P. et al. Dança e expressividade: uma aproximação com a fenomenologia. Movimento, Porto Alegre, v. 19, n. 1, p. 243-263, jan./mar. 2014.

MEDINA, J. P. S. A educação física cuida do corpo... e mente. 6. ed. Campinas: Papirus, 1983.

MORANDI, C. O ensino de dança nas escolas. In: STRAZZACAPPA, M.; MORANDI, C. Entre a arte e a docência: a formação do artista em dança. 4. ed. Campinas, SP: Papirus, 2006.

NANNI, D. Dança educação: pré-escola à universidade. 4. ed. Rio de Janeiro: Sprint, 2003.

NIETZCHE, F. Assim falou Zaratustra. Rio de Janeiro: Civilização Brasileira, 2005.

OLIVEIRA, V. M. O que é educação física. São Paulo: Brasiliense, 1983.

ROBLE, O. J. Reflexões sobre a dança a partir das metáforas de Zaratustra. efdeportes.com, Buenos Aires, ano 14, n. 131, abr. 2009. Disponível em: http://www.efdeportes.com/efd131/reflexoes-sobre-a-danca-a-partir-das-metaforas-de-

zaratustra.htm. Acesso em: 20 fev. 2017.

ROCHA, D. D.; REZER, R. Estética, formação inicial e dança: um olhar para a formação de professores de educação física. Movimento, Porto Alegre, v. 21, n. 4, p. 865-876, out./dez. 2015.

SBORQUIA, S. P.; GALLARDO, J. P. A dança no contexto da educação física. Ijuí: Uijuí, 2006.

SOARES, C. L. Educação física: raízes europeias e Brasil. Campinas: Autores Associados, 1994.

SOUZA, M. I. G. O ensino da dança na escola: técnica ou criatividade? Cadernos de Formação RBCE, v. 2, p. 32-42, 2011. 
STRAZZACAPPA, M. Dança na educação: discutindo questões básicas e polêmicas. Pensar a Prática, v. 6, p. 73-85, jul./jun. 2002-2003.

ZOTOVICI, S. A. Dança-educação: uma experiência vivida. Conexões: Educação, Esporte, Lazer, Campinas, n. 3, p. 119-28, dez. 1999.

Recebido em: $12 / 11 / 2017$

Revisado em: 06/06/2018

Aprovado em: 25/06/2018

Endereço para correspondência:

vitorhmarani@gmail.com

Vitor Hugo Marani

Universidade Federal de Mato Grosso, Campus Universitário do Araguaia.

Avenida Universitária, $\mathrm{n}^{\circ} 3.500$

Unidade Pontal do Araguaia

78698000 - Pontal do Araguaia, MT - Brasil 